\title{
Affirmation and Denial in Aristotle's De interpretatione
}

\author{
Mika Perälä ${ }^{1}$ D \\ Published online: 20 September 2019 \\ (c) The Author(s) 2019
}

\begin{abstract}
Modern logicians have complained that Aristotelian logic lacks a distinction between predication (including negation) and assertion, and that predication, according to the Aristotelians, implies assertion. The present paper addresses the question of whether this criticism can be levelled against Aristotle's logic. Based on a careful study of the De interpretatione, the paper shows that even if Aristotle defines what he calls simple assertion in terms of predication, he does not confound predication and assertion. That is because, first, he does not understand compound assertion in terms of predication, and secondly, he acknowledges non-assertive predicative thoughts that are truth-evaluable. Therefore, the implications of Aristotle's 'predication theory of assertion' are not as devastating as the critics believe.
\end{abstract}

Keywords Aristotle $\cdot$ Predication $\cdot$ Assertion $\cdot$ Affirmation $\cdot$ Denial $\cdot$ Negation

\section{Introduction}

In the De interpretatione (Int.), Aristotle holds that affirma-

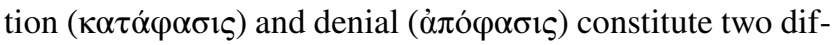
ferent kinds of assertion (áлó $\varphi \alpha \nu \sigma i \varsigma)$ or assertive sentence

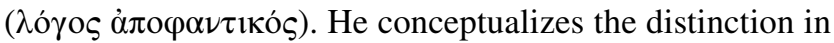
terms of combination ( $\sigma \dot{v} \nu \varepsilon \varepsilon \sigma \varsigma \varsigma)$ and separation, or division

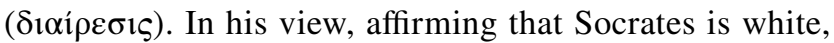
for example, requires combining being white with Socrates, whereas denying that he is white requires separating being white from him. The same distinction can be drawn in terms of two different kinds of belonging ( $\dot{\gamma} \pi \dot{\alpha} \rho \chi \varepsilon \imath$ ), or

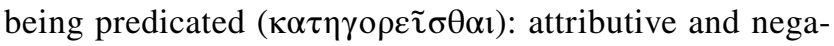
tive. Affirming that Socrates is white implies predicating being white of him, whereas denying that he is white implies negating being white of him.

At first sight, this seems to be a reasonable way of distinguishing between affirmation and denial. A problem is, however, that Aristotle seems to be committed to the converse implications, too. He gives the impression that predicating being white of Socrates implies affirming that he is white, and that negating being white of him implies denying that he

Mika Perälä

mika.perala@helsinki.fi

1 Department of Philosophy, History and Art Studies, University of Helsinki, P.O. Box 24, Unioninkatu 24 A, 00014 Helsinki, Finland is white. It is not clear why he should make this assumption. Indeed, the assumption appears to be a confusion. Therefore, it is not surprising that some modern logicians such as Gottlob Frege have complained that Aristotelian logic lacks an adequate distinction between predication (including negation) and assertion. ${ }^{1}$ Even if this criticism is not directly raised against Aristotle's logic, there are good grounds to raise doubts about Aristotle's position, too. It could be argued, for instance, that he is unable to differentiate the way in which we apprehend the predicative (i.e. propositional) contents of thought from the way in which we affirm or deny their truth. Furthermore, one might doubt whether Aristotle is able to differentiate the use of predication in a simple assertion from its uses in compound assertions such as conditional and disjunctive assertions. Hence, if the criticism is correct, Aristotle's logic and thereby cognitive theory is laid on feeble grounds.

The question I shall address in this paper is whether the foregoing criticism is well grounded. The focus of my discussion will be on what Aristotle calls simple assertions, that is, assertions which signify one thing of one thing (Int. $5,17 \mathrm{a} 15-16,20-21)$. In the case of simple assertions, I argue, Aristotle fails to make a clear distinction between predication and assertion. That is, as seen above, because

\footnotetext{
${ }^{1}$ See Frege (1919). Frege does not name his opponent, though. It is most likely, however, that he criticizes Bruno Bauch, who was his colleague in Jena. See Schlotter (2006). The points that Frege puts forward can be equally raised against Aristotle's considerations. For a discussion on some confusions in the De interpretatione, see Kneale and Kneale (1962, pp. 49-54).
} 
he accounts for assertion in terms of predication. I shall refer to this account as the 'predication theory of assertion'. However, it does not follow from this theory that Aristotle confounds predication and assertion. That is basically for two reasons. First, in the De interpretatione, Aristotle sets out to account for assertion or assertive sentence rather than predication, which is why one should be cautious in drawing any conclusions about Aristotle's view of predication in general. Note that Aristotle's phrase for an assertive sentence ( $\lambda$ ó $о \varsigma \varsigma \alpha \dot{\alpha} \pi \circ \varphi \alpha \nu \tau 1 \kappa o ́ \varsigma)$ suggests that he acknowledges a mere sentence ( $\lambda$ ó $\gamma \circ \varsigma$ ) that is not assertive. By the unqualified term 'sentence' ( $\lambda$ ó $\gamma \circ \varsigma$ ), he has in mind primarily the kinds of modes of speech that are not truth-evaluable, such as prayer, but he does not rule out non-assertive sentences that are truth-evaluable. ${ }^{2}$ There are other contexts in which he examines predicative thoughts, such as deliberating

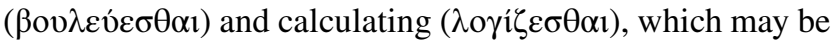
true or false but do not obviously imply assertion or denial in all cases, for instance, when one is conducting research but has not yet reached a conclusion (e.g. Ethica Nicomachea $6.9,1142 \mathrm{~b} 1-2)$. Secondly, not even in the De interpretatione does Aristotle confound predication and assertion. As I shall show, the distinction between the two is obvious insofar as compound assertions are concerned. Even if Aristotle does not discuss compound assertions in any detail-for instance, he does not discuss the truth conditions for compound assertions nor does he discuss the denials of compound assertions,$-{ }^{3}$ he makes no suggestion that when we assert, say, 'Socrates teaches and Plato learns', we also assert 'Socrates teaches' and 'Plato learns' separately. The conjunction in question involves two predications, but we only make one assertion. A conjunction may thus have unasserted parts. ${ }^{4} \mathrm{I}$

\footnotetext{
${ }^{2}$ For the contrast between assertion ( $\dot{\alpha} \pi$ ó $\left.\varphi \alpha \nu \sigma 1 \zeta\right)$ and sentence

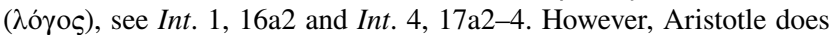
not use the term $\lambda$ óyos in referring to sentences only; in some cases, the term refers to a phrase such as 'a beautiful horse' (Int. 2, 16a22). Furthermore, Aristotle does not consider the modern distinction between sentence and statement in cases such as 'Socrates is white' and 'Sokrates ist weiß', in which there are two different sentences, but only one statement.

${ }^{3}$ See e.g. Geach (1972, pp. 15, 26). Geach gives a critical review of Aristotle's considerations on conjunctions not only in the De interpretatione, but also in some passages in the Sophistici elenchi and Analytica priora (APr.). In APr. 1.44, 50a40-b1, Aristotle promises to give an extensive account of arguments 'from hypothesis' ( $\dot{\varepsilon} \xi$ vं this topic, see Barnes (1985).

4 This is an implication of what Geach (1972, pp. 13-14) takes to be a defining feature of what he calls 'the classical doctrine of the conjunctive proposition'. Geach claims: 'Like any other proposition, a conjunction may occur as an unasserted part, e.g. as an if or then clause, of a longer proposition' (Geach's emphasis). From the claim that any proposition may occur as an unasserted part of a longer proposition, it follows that the propositions that constitute the conjunction may occur as unasserted parts. This is not to suggest that Aristotle would deny, for the reasons just given, the principle of conjunction
}

assume that the same applies to other compound assertions such as the conditional 'If Socrates teaches, Plato learns'. ${ }^{5}$ It follows that simple assertion and compound assertion constitute different kinds of single assertions. Aristotle expresses this implication as follows: 'A single assertive sentence is either one that reveals a single thing or one that is single in virtue of a connective' (17a15-16; trans. Ackrill, modified). ${ }^{6}$

The foregoing considerations suggest that the implications of the predication theory of assertion are not as devastating as the critics believe. As soon as we see the qualifications that Aristotle makes to this theory, the theory no longer looks outrightly false, and the criticism loses some of its power. The aim in this paper is thus twofold: on the one hand, I discuss the qualifications that Aristotle makes to the predication theory of assertion, and on the other, I consider whether and how we can address the criticism levelled against that theory. The focus of this paper lies on the De interpretatione; other texts will be consulted only for the sake of comparison and contrast. ${ }^{7}$

\section{Footnote 4 (continued)}

elimination, i.e. the inference from ' $p$ and $q$ ' to ' $p$ ' (and to ' $q$ '). We do not know about his view of this inference or other similar inferences based on a single premise, because he does not discuss such cases. The point that I wish to make is rather that it is one thing to assert ' $p$ and $q$ ' and another thing to assert ' $p$ ' and ' $q$ ' separately, because the proposition ' $p$ and $q$ ' is a single unit (as in 'if $p$ and $q$, then $r$ ') that is different from the pair of separate propositions ' $p$ ' and ' $q$ '.

${ }^{5}$ In the case of the conditional, it is perhaps easier to see why the compound assertion does not imply assertion of each of its elements.

${ }^{6}$ Here I follow the interpretation that is shared by all ancient commentators (Ammonius In Int. 66.31-67.19; 73.15-74.14; Boethius In Int. sec. ed. 96.28-97.18; 105.1-18; 115.23-116.6; Stephanus In Int. 20.4-10; 20.16-24; anon. In Int. 18.7-19). The same interpretation can be found in some medieval commentators (e.g. Thomas Aquinas, Expositio libri Peryermenias I 8, 192-198, 261-277) as well as some modern interpreters, e.g. Crivelli (2004, p. 172), and Weidemann (2014, pp. 193-197). However, other modern commentators, e.g. Lukasiewicz (1954, pp. 131-132), and Bobzien (2002, p. 364), assume that Aristotle does not allow a single assertion to consist of sentences combined by connective particles. Presumably, they make this assumption because Aristotle overlooks compound assertions in his discussion of demonstration in the Analytics. However, this reason is not convincing because the scope of the De interpretatione is broader than the theory of demonstration. For a very helpful note on further references, see Crivelli (2004, p. 172 n. 72).

7 Hence, I do not assume that Aristotle's considerations in the De interpretatione are entirely in line with e.g. the Analytica priora. For a helpful recent account of assertion that is mainly based on the Analytica priora, see Crivelli (2012, pp. 113-124). 


\section{Truth and Falsity, Combination and Separation}

In the beginning of the De interpretatione, Aristotle proposes the following analogy between speech and thought:

Just as some thoughts in the soul are neither true nor false while some are necessarily one or the other, so also with spoken sounds. For falsity and truth have to do with combination and separation. Thus names and verbs by themselves-for instance 'man' or 'white' when nothing further is added-are like the thoughts that are without combination and separation; for so far they are neither true nor false. $(16 a 9-16)^{8}$

The proposal put forward here is that there are two kinds of locutions and thoughts: those that are either true or false, and those that are neither true nor false. This distinction between being a truth-bearer and not being a truth-bearer is fundamental. Thoughts and locutions that are not capable of being truth-bearers include thoughts and locutions about single items such as man, being white or a two-footed animal. Such thoughts are concepts which correspond to single terms or expressions in a language. Even if they are constituents of true and false thoughts and locutions, they do not in and of themselves constitute affirmations and denials, the topic of the present paper. In what follows, therefore, the focus will be on the kind of locutions and thoughts that can be truth-bearers and hence are truth-evaluable.

Aristotle claims that being true or false involves some

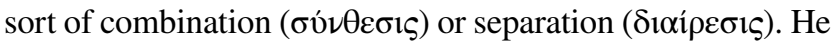
does not specify what he means by 'combination' and 'separation' here, but the context suggests the following. In the case of speech, what we combine and separate are typically names and verbs. For instance, when we combine 'being white' with 'Socrates', we say, 'Socrates is white', which is either true or false depending on whether Socrates is in fact white or not. Similarly, when we separate 'being white' from 'Socrates' by using a negation, we say, 'Socrates is not white', which is either true or false depending on whether Socrates is in fact white or not.

In the present context, Aristotle does not explain how the proposed analogy with thoughts ( $\nu$ on $\mu \alpha \tau \alpha)$ works, but we can begin with the following suggestion. When we combine the concept of being white with the mental correlate of the name 'Socrates', we think that Socrates is white. By analogy, when we separate the concept of being white from the notion of Socrates, we think that Socrates is not white. The composite thoughts involved are either true or false depending on whether Socrates is in fact white or not.

\footnotetext{
8 All the translations of the Int. are from Ackrill (1963); all other translations are mine unless otherwise indicated.
}

The claim that being true and false implies some sort of combination originates from Plato's Sophist. There the Eleatic Visitor suggests that the most basic statement arises

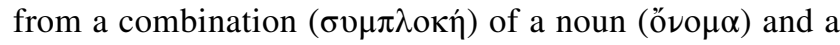
verb $(\dot{\rho} \tilde{\eta} \mu \alpha)$. For example, when one combines the noun 'man' with the verb 'learns', one produces the statement 'Man learns' (262c9). A further example Plato gives is the statement 'Theaetetus sits' (263a2). The two examples suggest that in Plato's view, the noun may be a proper name or a common noun.

How do Aristotle's considerations relate to Plato's? Aristotle generalizes Plato's point about the combination of a noun and a verb. In Aristotle's view, simple assertion may consist not only of a noun and a verb but also of a noun and a verbal phrase such as 'is just'. In Int. 10, 19b24-25,

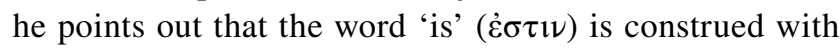
the predicate term rather than with both the subject and the predicate terms (as is the case in the Analytics in which Aristotle takes the word 'is' to be a copula, and therefore rejects the syntax of the Sophist). Although there is some evidence to the contrary (e.g. 19b19-22; 21b27-28, which point in the direction of the Analytics), it is reasonable to suppose that in the De interpretatione Aristotle is advancing Plato's analysis of simple assertion. ${ }^{9}$ Additionally, he makes further divisions between the different kinds of assertion. Apart from affirmative and negative assertions, he distinguishes between simple and compound assertions, between singular and general (either universal or particular) assertions, and between categorical, apodictic and problematic assertions. In what follows, the focus will be on the distinction between affirmative and negative assertions on the one hand, and simple and compound assertions on the other.

The claim that being true and false implies combination and separation sets Aristotle's view of truth-bearers apart from some later developments. Whilst Aristotle takes the bearers of truth-values to be linguistic, mental or even mindindependent composite entities, that is, locutions, thoughts or Socrates being white (or the fact that Socrates is white), for example, many of his critics, such as the early Stoics and Frege, claim them to be exclusively mind-independent propositions. ${ }^{10}$

\footnotetext{
9 For more detailed considerations in support of this interpretation, see Barnes (1996, pp. 187-192).

${ }^{10}$ I am referring to Frege (1918). For the Stoics, see e.g. Diogenes Laertius 7.65 and Sextus Empiricus Adversus mathematicos 8.74. I say 'even mind-independent composite entities' because it is controversial whether Aristotle, in Metaph. $\Delta .29,1024 \mathrm{~b} 17-21$, and $\Theta .10$, 1051b1-3, attributes truth and falsity to the composite objects of thoughts and locutions. For a positive answer to this question, see e.g. Crivelli (2004, pp. 46-62); for a negative, see e.g. Charles and Peramatzis (2016). This issue is significant because in Metaph. E.4 Aristotle says in contrast that 'falsity and truth are not in objects [...] but in thought' (1027b28-29). However, nothing of importance for the present paper depends on adjudicating this issue.
} 
Aristotle thus claims that true and false locutions and thoughts imply a requisite sort of combination or separation. He contrasts such locutions and thoughts with those that are neither true nor false (16a13-16). The implication is that such locutions and thoughts are neither true nor false because they do not arise from a relevant sort of combination or separation. It is reasonable to assume that the locutions and thoughts in question include those that entirely lack combination and separation because they consist of single concepts and terms that are constituents of combination and separation. These are the cases that Aristotle pays most attention to. However, he also acknowledges locutions and thoughts that involve a different, non-assertive sort of combination or separation, namely questions, commands, prayers and the like (Int. 4, 17a2-7). In his view, then, it is only a certain kind of combination or separation that gives rise to true and false locutions and thoughts. ${ }^{11}$

The foregoing considerations have shown that all true and false locutions and thoughts involve a specific kind of combination or separation. But nothing said thus far suggests that all true or false locutions and thoughts imply an affirmation or denial. This is a controversial implication. In what follows, I shall argue that Aristotle is not committed to that implication without qualification. I have already mentioned that in some contexts outside the De interpretatione, for instance, when discussing the nature of research and deliberation, Aristotle acknowledges non-assertive locutions and thoughts. However, there is some evidence that he distinguishes between predication and assertion even in the De interpretatione. Even if he fails to make a clear distinction between the two in the case of simple (i.e. categorical) assertions, he separates them in the case of compound (i.e. hypothetical) assertions.

\section{Simple and Compound Assertions}

In Int. 4 Aristotle claims, 'A sentence is a significant spoken sound some part of which is significant in separationas an expression, not as an affirmation' (16b26-28; trans.

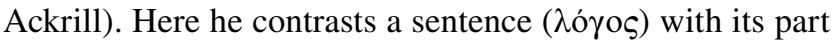
that remains a significant expression ( $\varphi \alpha ́ \sigma 1 \varsigma)$ even when it is

\footnotetext{
11 In commenting on Int. 1, 16a9-18 (the passage quoted above in part), Ammonius points out this implication succinctly, thus: 'So truth and falsity are wholly concerned with combination and division, but not every combination or division accepts one or the other of these. In fact, one who wishes or uses any other sentence besides the assertoric combines names and verbs while saying nothing either true or false. But the combination or division must be of the "belonging" (iं $\alpha \propto \kappa \tau$ เ does not belong to another, a character seen only with regard to the assertoric sentence.' (In Int. 27, 8-14; trans. Blank)
}

removed from the sentence. ${ }^{12}$ For instance, 'an animal' signifies an animal even when it is separated from a sentence, but it constitutes neither the affirmation 'An animal exists', nor the denial 'An animal does not exist', for example, unless it is combined with the predicate. By adding 'as an expression, not as an affirmation', he points out that an expression that is part of a sentence does not constitute in separation an affirmation or, for that matter, a denial. This suggests that Aristotle is characterizing here a simple sentence rather than a compound sentence, parts of which constitute affirmations or denials in separation. Consider, for example, the compound sentence 'If Socrates teaches, Plato learns'. The expression 'Socrates teaches' constitutes an affirmation if it is taken out of the sentence. However, if it is part of the compound sentence, it does not constitute an affirmation. I shall suggest in a moment that Aristotle treats in this way all those assertions that are compounded by sentential connectives such as 'if', 'or', and 'and'. In other words, compound assertion, according to Aristotle, constitutes a single assertion rather than several assertions.

In the present context, Aristotle focuses on assertive sentences. He proceeds to explain what is distinctive of assertive sentences, thus: 'Every sentence is significant $[. .$.$] by$ convention but not every sentence is assertive, but only those in which there is truth or falsity' (16b33-17a3; trans. modified). A straightforward interpretation of this claim is that if a sentence is true or false, it is assertive. In other words, all true or false sentences are assertions. The immediate context seems to support this interpretation: 'There is not truth or falsity in all sentences: a prayer is a sentence, but is neither true or false' (17a3-4). The fact that Aristotle contrasts here true and false sentences with non-assertive sentences such as prayers that have no truth-value suggests that he takes all true and false sentences to be assertions. ${ }^{13}$ But this cannot

${ }^{12}$ In the sentence quoted, then, Aristotle uses the term 'expression' ( $\varphi \alpha ́ \sigma 1 \varsigma)$ in signifying a subsentential expression. That is why the contrast he draws here is between a subsentential expression and an affirmation, rather than between a sentence that is not affirmed and an affirmation. It is not entirely clear which of the two Aristotle has

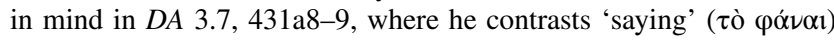

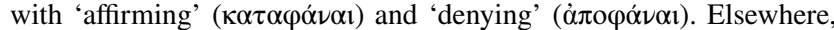
he tends to use the term $\varphi \alpha ́ \sigma 1 \varsigma$ in signifying either an affirmation (e.g. Int. 12, 21b21-22; APr. 1.46, 51b20, 2.11, 62a14; Metaph. $\Gamma .4,1008$ a9), or more generally an assertion, including affirmation and denial (e.g. Int. 12, 21b19, 22a11; Metaph. Г.6, 1011b14, K.5, 1062a6).

${ }^{13}$ It is not entirely clear why Aristotle says that a prayer has no truthvalue. In Int. 9, 18a33-34, he claims that sentences about singular states of affairs in the future have no truth-value, and he may assume that prayers are among these sentences. I do not think, however, that this is the reason why he denies truth-value to a prayer. Since Aristotle, in the passage cited above, gives prayer only as one example of a non-truth-evaluable sentence, I assume that he takes it to be analogous with other similar sentences such as a wish or a command which are not expressed in the indicative mood that is confined to factual statements, i.e. assertions that are true or false. Instead, in Aristotle's 
be correct. And that is not Aristotle's view, or so I argue. For instance, the false sentence 'The sun is a foot across' does not constitute an assertion if a perceiver uses it to express in a predicative form what appears to her when she is looking at the sun, but does not in fact believe that the sun is a foot across. To give a plausible account of assertion, therefore, Aristotle ought to place some further requirements for a true or false sentence to count as assertive. And he does that, even if, as we shall see, he does not give a complete account of the matter in the De interpretatione.

In the subsequent two chapters, Aristotle specifies how he understands the nature of assertion. First, in Int. 5, he draws the distinction between an affirmative and negative assertion, thus: 'The first single assertive sentence is the affirmation, next is the denial' (17a8; trans. modified). Affirmation and denial are given here as different kinds of the single asser-

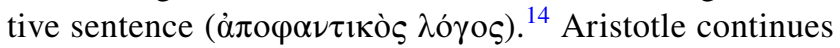
by stating, 'Every assertive sentence must contain a verb or an inflection of a verb' (17a9; trans. modified). That is a syntactic requirement for being an assertive sentence. The contrast between 'verb' and 'inflection of a verb' is between the present tense and the other tenses. Even if some universal statements such as 'All men are mortal' constitute eternal and hence in a way timeless truths, they are nevertheless tensed in a semantic analysis. ${ }^{15} \mathrm{~A}$ couple of lines later, he adds two further, alternative requirements, which I have already quoted in the introduction of the present paper: 'A single assertive sentence is either one that reveals a single thing or one that is single in virtue of a connective' (17a15; trans. modified). ${ }^{16}$

\footnotetext{
Footnote 13 (continued)

Greek, the act of wishing is expressed in the subjunctive mood, and the act of command in the imperative mood. I am thus suggesting that in contrasting prayers with truth-evaluable sentences, Aristotle follows colloquial speech in which the distinction between factual and non-factual sentences is drawn in terms of the indicative mood and the other moods, including the subjunctive and the imperative.

14 The fact that Aristotle mentions affirmation first gave rise to an issue on the status of an assertive sentence in the commentary tradition. Alexander of Aphrodisias, it is told, argued that if affirmation is prior to denial then the two cannot be species of the same genus. Ammonius and Boethius rejected Alexander's argument. For their criticism of Alexander, see Ammonius In Int. 67, 30-68, 9; Boethius In Int. sec. ed. 98, 15-99, 12.

15 Consider, for instance, 'The simple statement is a significant spoken sound about whether something does or does not hold in one of the divisions of time' (17a23-24). Ackrill puts the expression that I have italicized in brackets, but that is misleading because Aristotle wishes to underline here the point that simple assertions are basically tensed assertions.

${ }^{16}$ Substantially the same two requirements are put forward in $D e$ arte poetica $20,1457 \mathrm{a} 28-30$ and APo. 2.10, 93b35-37. For a discussion, see Barnes (2007, pp. 178-180).
}

The first requirement is semantic by nature. It requires that a single assertion reveals a single thing. I take this to mean that a single assertion signifies one thing about one thing. This point is confirmed in Int. 8. There Aristotle adds that a single assertion signifies one thing about one thing, 'whether about a universal taken universally or not' (18a13). In his view, then, a universal assertion such as 'All men are white' constitutes just a single assertion, even if it implies that the predicate is affirmed of each man. ${ }^{17}$ Further, in Int. 11, Aristotle puts forward considerations on how several predicates can constitute a compound predicate that signifies one thing rather than several things. More specifically, the question Aristotle discusses is under which conditions it is legitimate to infer from the claims that $a$ is $F$ and $G$ the claim that $a$ is $F G$, where $F G$ signifies one thing (20b31-33). Aristotle notes, for instance, that it is not legitimate to infer from someone being good and a cobbler that he is a good cobbler (b35-36). That is presumably because the person in question may not be good insofar as he is a cobbler. He may, for example, be a good father, but a poor cobbler. In this case, then, the attribute 'good' does not qualify the attribute 'cobbler'; it rather qualifies directly the person who happens to be a cobbler. Hence, even if it is correct to say that the cobbler is good, that is true only because the person who happens to be a cobbler is good. In other words, the cobbler is good merely accidentally ( $\kappa \alpha \tau \grave{\alpha} \sigma v \mu \beta \varepsilon \beta \eta \kappa o ́ s$, 21a8). ${ }^{18}$ Further examples clarify the matter. It is incorrect to infer from someone being educated and white that he is an educated white (a9-14). The compound predicate 'educated white' fails to single out one thing, because 'educated' does not specify 'white'; it merely qualifies the subject, a man. Hence, even if it is correct to say that the educated man is white, that is true only because the man who happens to be educated is white. In other words, the educated man

\footnotetext{
${ }^{17}$ In APo. 1.1, Aristotle further specifies the matter, thus: 'We speak of "being predicated of all" when nothing can be found of the subject of which the other will not be said, and the same account holds for "of none"" (24b29-30; trans. Striker). An implication of this specification is that universal affirmation does not constitute a simple assertion, but rather a compound assertion. So even if Aristotle considers universal affirmation to be single, he does not regard it as simple in a semantic analysis. I shall discuss this matter in more detail in Sect. 4.

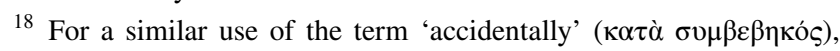
see e.g. Cat. 6, 5a38-b10; APo. 1.22, 83a1-21; DA 2.6, 418a20-23. This usage is to be contrasted with the way in which a non-essential property (i.e. accident, $\tau$ ò $\sigma 0 \mu \beta \varepsilon \beta \eta \kappa o ́ \varsigma)$ is said to belong to a substance, e.g. the property of being white to a man. For this use, see e.g. Metaph. Г.4, 1007a31-34; APo. 1.4, 73a34-b5. Weidemann (2014, p. 381), notes correctly that in Metaph. $\Delta .7,1017 \mathrm{a} 7-22$, Aristotle uses

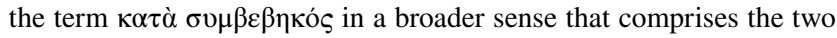
usages just mentioned.
} 
is white merely accidentally. By contrast, it is correct to infer from something being two-footed and an animal that it is a two-footed animal (20b33-34). That is because the predicate 'two-footed' specifies 'animal', and thereby the compound predicate 'two-footed animal' signifies one thing. These considerations suggest the following generalization: if the elements of the compound predicate determine each other, the predicate signifies a unity; if the elements do not determine each other, but do determine the subject directly, the predicate does not signify a unity. In the latter case, the attributes are independent of each other and merely co-occur in the subject. ${ }^{19}$

An advantage of this interpretation is that it helps to explain why Aristotle, somewhat surprisingly, considers the predicate 'white man' to single out one feature of the subject (20b34-35). The explanation is that Aristotle takes the attribute 'white' to specify 'man' rather than the subject, say, Socrates. In the present case, then, he does not require that the one feature singled out by the predicate 'white man' be a natural kind, and yet he insists that that feature constitutes a unity. ${ }^{20}$ Being a white man is indeed one way of being as opposed to being a black man, for example. ${ }^{21}$ It can be concluded that Aristotle contrasts single assertions with several assertions by contrasting predicates signifying unities with predicates signifying accidental compounds.

The second requirement is syntactic by nature. It requires that a single assertion constitutes a single thing in virtue of a connective. Aristotle does not determine the relationship between the two requirements. It is reasonable to assume, however, that the assertions that are compounded by a connective are assertions that satisfy the first requirement. If that were not the case, compound assertions would not be single

\footnotetext{
${ }^{19}$ I take this generalization to be Aristotle's answer to the question of what the difference is between the two types of compound predicates, i.e. those that signify a unity and those that do not (20b31-33). By giving this answer, Aristotle does not give a general rule to decide whether an element of a given compound predicate determines another element or not. Hence, Aristotle does not explain when it is legitimate to pass from separate predicates to a compound predicate. That is why I agree with Ackrill (1963, p. 148), who concludes his commentary of the passage in question by saying that 'no general rule has been given as to which predicates function, when combined with others, as "good" does in "good cobbler". For further considerations in support of this interpretation, see Weidemann (2014, pp. 385-387).

${ }^{20}$ Here, again, I am following Ackrill (1963, p. 147), who notes, correctly, 'Yet "white man" is an excellent example of what is not a real or natural unity like "two-footed animal"' (Ackrill's emphasis).

${ }^{21}$ In the beginning of Int. 11, however, Aristotle denies that the attributes 'white', 'man' and 'walking' succeed in signifying a unity (20b18-19). It is not entirely clear how this denial is to be interpreted in the light of the subsequent considerations in the same chapter. It is reasonable to suppose, however, that Aristotle considers this case to be analogous with a man being white and educated (21a10)
}

in a fundamental sense, because their components would be analysable into more basic assertions.

In the second requirement, the term 'connective' is ambiguous. I take that to be intentional on Aristotle's part. By that term, he refers not only to predicative connectives in cases such as 'Man is two-footed and an animal' and 'Man is educated and white', but also to sentential connectives in cases such as 'Man is two-footed and man is an animal' and 'Man is educated and man is white'. There is a connection between the two types of cases because the former assertions imply the latter ones. The point Aristotle wishes to make here is that not only a simple assertion but also a compound assertion constitutes a single assertion. That is why he contrasts these assertions with those that fail to be single. In the present case, the lack of a connective explains why there is more than one assertion in cases such as 'Man is two-footed. Man is an animal' and 'Man is educated. Man is white'.

The two further requirements, as Ackrill correctly notes, seem to be inconsistent. ${ }^{22}$ It follows from the first requirement that 'Man is an educated white' does not count as a single assertion, whereas the second requirement treats the assertion 'Man is educated and white' as a single assertion. The inconsistency is merely apparent, however, because Aristotle understands the single assertion in the two cases in a different way, or so I argue. The argument, then, is that what it is to be a single assertion for a simple assertion is different from what it is to be a single assertion for a compound assertion. In the first case, a single assertion consists of a certain kind of combination or separation, i.e. attributive or negative predication, whereas in the second case, it is achieved through a requisite connective. Since the two requirements imply a different understanding of single assertion, there is no discrepancy between them. Note that Aristotle needs both requirements because there must be some criteria to decide whether any given assertion is single or not. The second requirement is particularly important. Unless he accepts it, he will be unable to give a satisfying account of compound assertions (i.e. hypothetical assertions) and thus address the issue I mentioned in the introduction. Before we can address that issue, we need to look closer at the distinction Aristotle makes between simple and compound assertions. That helps to further clarify the basic distinction he draws between affirmation and denial.

As mentioned, Aristotle divides assertive sentences into simple and compound. He says, 'Of these the one is a simple assertion, affirming or denying something of something, the other is compounded of those [simple assertions] and is a kind of composite assertion' (17a20-22; trans. modified). Now the way in which Aristotle characterizes simple assertion sheds further light on his understanding of the nature

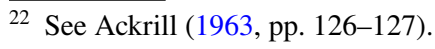


of assertion. Here, he conceives of affirmation as a kind of predication rather than as the acceptance of a predicative sentence. He accounts for affirmation in terms of affirming something of something rather than in terms of affirming that something is the case, i.e. that $S$ is $P$. That is because he assumes that affirmation consists in taking the predicate to be true of the subject, that is, combining the predicate with the subject in a distinctive way. Likewise, he accounts for denial in terms of denying something of something rather than in terms of denying that $S$ is $P$. He thus assumes that denial consists in taking the predicate to be false of the subject, that is, separating the predicate from the subject in a relevant way. For these reasons, I find it appropriate to call Aristotle's view of simple assertion a predication theory of assertion. However, I am not suggesting that he takes all kinds of predication to imply assertion. I shall return to this matter in a moment. I shall also return to his view of compound assertion to explain why he does not take the elements of compound assertion to be assertions in their own right.

It should be clear from the foregoing considerations that Aristotle's predication theory can be contrasted with, for example, the Stoic and Fregean theories in which assertion takes as its object a complete proposition. ${ }^{23}$ However, the foregoing considerations do not imply that Aristotle considers it illegitimate to use propositional phrases such as 'I affirm that $S$ is $P$ ' or 'I deny that $S$ is $P$ ' in referring to assertions. The point is just that he does not regard these formulations as being logically basic. They can be reduced to assertions with a predicative structure.

I will conclude this section by pointing out two implications of Aristotle's considerations about simple assertion. First, from the assumption that denial consists in separating the predicate from the subject, it follows that the correct logical form of denial is ' $S$ is not $P$ ' rather than 'It is not the case that $S$ is $P^{\prime}{ }^{24}$ That is so even if Aristotle is in the habit

\footnotetext{
${ }^{23}$ For a testimony on the Stoic view, see Stobaeus Anthologium 2.88,

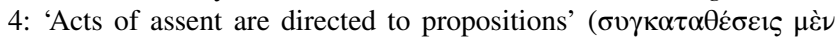

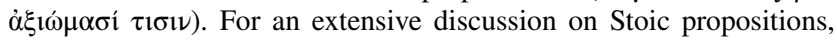
see Frede (1974, pp. 32-44). Having shown that question and answer, i.e. assertion, contain the same proposition or thought (Gedanke), Frege (1918, p. 62) concludes by pointing out what is distinctive of assertion: 'In einem Behauptungssatz ist also zweierlei zu unterscheiden: der Inhalt, den er mit der entsprechenden Satzfrage gemein, hat und die Behauptung.' He thus assumes that assertion consists in an assent to a proposition.

24 See e.g. Barnes (1986, p. 202), who discusses Alexander of Aphrodisias' view about the denials of singular affirmations. These denials are simple assertions. It does not follow that the general (quantified) denials, i.e. universal and particular denials, can be analysed in the same way. I shall suggest below (Sect. 4) that in a semantic analysis, according to Aristotle, quantified assertions are compound assertions, and that they require a sentential negation ('It is not the case that...').
}

of formulating denials by prefixing the negative particle to the entire sentence. ${ }^{25}$ Secondly, from the assumption that all simple assertions are either affirmations or denials in the proposed way, it follows that also simple existential assertions ought to be accounted for in predicative terms. It is not entirely clear, however, whether Aristotle succeeds in explaining existential assertions in predicative terms (Int. $10,19 \mathrm{~b} 14-19)$. It is beyond the scope of the present paper to review the merits of Aristotle's theory in this respect. Let it suffice to say that at the very least, he has resources to address the issue, if not to settle it. As Crivelli has pointed out, Aristotle can qualify the way in which we affirm (or deny) Socrates to exist, saying, for example, that this consists in affirming (or denying) his form to be combined with matter. ${ }^{26}$ Let me note a further obscurity in Aristotle's considerations. It is not clear whether affirmation and denial, considered from a cognitive point of view, require more than an act of predication. In other words, it is not clear whether an act of predication suffices to constitute an affirmation or a denial. Aristotle does not discuss this question in the $D e$ interpretatione. However, his discussion of compound assertion suggests that predication is not sufficient for affirmation and denial. I shall proceed to discuss this matter next.

\section{Further Consideration of Compound Assertions}

The considerations put forward in the preceding two sections suggest that Aristotle has resources to address the criticism levelled against the predication theory of assertion. By exploiting those resources, I hope to have shown that he does not fail to distinguish between predication and assertion nor is he unable to differentiate the use of predication in a simple assertion from its use in a compound assertion. It is fair to admit, however, that Aristotle himself does not use those resources to address the criticism in any detail. In the De interpretatione, he does not discuss truth-evaluable sentences other than those that are assertive. Moreover, in one case he even seems to contradict himself when he suggests, as seen above, that complex assertion is 'compounded

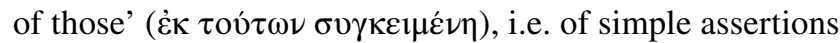
(17a21). However, this appears to be a single unhappy formulation which is not repeated elsewhere. Therefore, it does not suffice to call into question the argument that I have pursued thus far.

Nonetheless, the argument proposed needs to be further clarified and examined. Let me first clarify the distinction

\footnotetext{
${ }_{25}$ See e.g. Int. 7, 17b10, 25, 28-29, 18a2-7; Int. 10, 19b32-35, 20a5-7.

${ }^{26}$ See Crivelli (2004, p. 124).
} 
between predication and assertion in the two cases under study: simple assertion and compound assertion. In simple assertion, as suggested, assertion is a certain kind of predication. In this case, then, we can regard the predication involved as being assertive. It does not follow that all predications are assertive, although Aristotle fails to emphasize this point in the case of simple assertion. In compound assertion, by contrast, predication and assertion are for obvious reasons different because, as seen, asserting 'If Socrates teaches, Plato learns' does not imply asserting 'Socrates teaches' and 'Plato learns', and yet it implies making two predications. In this case, then, the predications involved are to be regarded as being non-assertive, and yet capable of being true or false because they are combinations of terms. Even if Aristotle does not give an account of the different types of compound assertions, including conjunctions and disjunctions, it is reasonable to assume that the same analysis applies to both of them. ${ }^{27}$ Further, it is reasonable to assume that the compound assertion itself does not constitute a predication because it is not a combination or separation of terms. However, compound assertion is a combination or separation of sentences, and that is why it is an assertion that can be true or false.

Let me make a second clarifying remark about the distinction between affirmation and denial in simple and compound cases. In the simple case, Aristotle understands the distinction between affirmation and denial in terms of certain kinds of combination and separation, that is, affirmative and negative predication. In the compound case, however, a comparable account cannot be given, because compound assertions are not predications. Rather, as noted above, they are combinations and separations of sentences, compounded by relevant kinds of connectives. The question that we need to raise here is whether this characterization constitutes a reasonable account of compound assertion. I shall address this question by considering two more specific questions: first, how Aristotle would account for negative compound assertions (i.e. compound denials), and second, how he would reduce those assertions that are presented in the form of a simple assertion but which are genuine compound assertions to compound assertions. Since Aristotle, as mentioned, does not give an account of compound assertions, it would be pointless to try to answer these questions in a

\footnotetext{
27 In commenting on Int. 5, 17a15-17, Ammonius (In Int. 73.1574.14) denies that some conjunctions such as 'Socrates sits and Alcibiades walks' constitute a single (compound) affirmation. That is because, he says, the two predications are united only on account of expression; they do not signify a unity in reality. It is not entirely clear whether he takes all conjunctions to be of this type. However, he notes that the conditional 'If god is good, the universe is eternal', and the disjunctive 'The universe is either eternal or created' are single (compound) affirmations, and signify a unity. That is because the for-

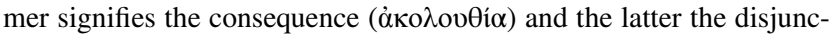

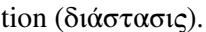

systematic manner. Therefore, I shall focus on some examples that help to point out the distinctive features of the approach to which Aristotle is committed.

Regarding the question about compound denials, consider the denial of 'If Socrates teaches, Plato learns'. According to a reasonable modern understanding of the conditional ('If $p$, $q$ '), say, Frege's understanding, the affirmation of the conditional consists in affirming the truth of the inclusive disjunction between the negation of the antecedent and the consequent ('not- $p$ or $q$ '), whereas the denial of the conditional consists in affirming the truth of the conjunction of the antecedent and the negation of the consequent (' $p$ and not- $q$ '). In this understanding, then, the denial of the given conditional implies affirming the conjunction 'Socrates teaches and not: Plato learns'. As Frege insists, there is no need to postulate a distinct negative act of judgement because denial can be accounted for in terms of an affirmative act with a negated proposition. By contrast, Aristotle postulates an act of denial. The question that interests us for the present is whether he needs to refer to that act in explaining the denial of the conditional. The subsequent considerations suggest that he need not do so.

Suppose that Aristotle formulates the denial of the conditional in question in terms of two predications with a connective: 'Socrates teaches and Plato does not learn'. The first predication is attributive, whereas the second is negative. Neither of the two is an assertion because they are elements of a compound assertion. Now, since the connective here is a conjunction that conjoins the two predications, it is reasonable to suggest by analogy with simple affirmation (which consists of a combination of the subject and predicate terms) that the assertion that we make here is an affirmation. Hence, the analysis suggests that Aristotle need not refer to the act of denial in explaining the denial of a conditional. However, a similar analysis suggests that he must refer to that act in explaining the affirmation of a conditional. That is because the affirmation in question is given in terms of the disjunction 'Socrates does not teach or Plato learns', and the disjunctive connective involved is most reasonably seen to separate the two predications. In this case, too, the suggestion is based on the analogy with a simple denial, which consists of a separation of the predicate term from the subject term. In the compound case in question, the denial consists of a separation of one predication from the other. The case is mixed in that one of those predications is negative and the other affirmative.

The foregoing considerations show that Aristotle has resources to account for both affirmation and denial of the conditional. I have assumed above that Aristotle would analyse the conditional 'If...then...' in terms of conjunction and disjunction, taking the two to correspond to affirmative and negative acts of judgement. If he found it unnecessary to posit other connectives beyond conjunction and disjunction, and if he took the double negation to be identical to 
affirmation, he would have sufficient resources to account for all basic compound assertions. By 'basic compound assertions', I refer to those compound assertions that include only one connective, either conjunction or disjunction, and hence are not mixtures of conjunctions and disjunctions, for example '(Socrates teaches and Plato does not learn) or Plato learns'. In analysing basic compound assertions, then, Aristotle applies four basic concepts: attributive predication, negative predication, affirmation and denial. Note that this is in fact less than what Frege posits in his analysis of compound assertions: proposition, negation, conjunction, disjunction, and affirmation. It does not follow, however, that Aristotle's approach is simpler than Frege's. That is because Aristotle is compelled to set the affirmations and denials in a hierarchy to analyse mixed compound assertions. In the above example, the affirmation indicated by the conjunctive particle 'and' is subordinate to the denial indicated by the disjunctive 'or'. That means that it loses its affirmative force in a way analogous to a predication embedded in a compound assertion. This is because a mixed compound assertion ought to constitute a single assertion rather than several assertions.

I then proceed to address the question of how Aristotle would reduce those assertions that are presented in the form of a simple assertion but which are compound assertions to compound assertions. Consider the universal denial 'No man is white educated'. ${ }^{28}$ This denial looks like a simple denial, but it is not because of the complex predicate term. The denial cannot be reduced to the compound denial 'No man is white and no man is educated' because this denial and the original one do not mean the same. It does not follow, however, that the original cannot be analysed into a compound assertion at all. On the contrary, such an analysis can be given, or so I argue. ${ }^{29}$ In fact, a similar analysis can be given for all quantified assertions, whether they have complex predicates or not. Given that, the universal denial 'No man is white' which is overtly a simple denial could be reduced to a complex one. For a deeper understanding of the matter, however, we need to make a brief digression to the Analytica priora. There Aristotle analyses the meaning

\footnotetext{
28 The expression 'white educated' is ambiguous, but the denial in question should be understood as saying, 'No man who is white is educated'.

29 This is where I disagree with Weidemann (2014, p. 197), who notes, correctly, that the universal denial 'No man is educated white' cannot be analysed into 'No man is white and no man is educated'. However, he is mistaken, along with Ackrill (1963, p. 126) and Geach (1972, p. 47), in his further remark that the denial in question cannot be analysed into any other complex of simple claims either. That claim is true only of Aristotle's considerations in the Int. However, as I argue below, Aristotle has resources to account for overtly simple quantified assertions in terms of compound assertions in the Analytica priora.
}

of the quantified predications 'being predicated of all' and 'being predicated of some' in compound terms. I suggest that he would be consistent in considering all quantified predications to be compound assertions in accordance with their semantic complexity.

In $A P r .1 .1$, Aristotle concludes his discussion of predication, thus: "We speak of "being predicated of all" when nothing can be found of the subject of which the other will not be said, and the same account holds for "of none" (24b29-30; trans. Striker). The fact that Aristotle characterizes not only universal denial but also universal affirmation in negative terms ('nothing can be found') is somewhat startling. However, his phrasing can be explained if we assume that he refers to an arbitrary individual, say $z$, of which a negative claim is made. In this interpretation, Aristotle's conclusion yields the following characterizations of universal affirmation ('Every $S$ is $P$ ') and universal denial ('No $S$ is $P$ '):

For every term $S$, for every term $P$, every $S$ is $P$ if and only if it is not the case that for some $z, S$ is predicated of $z$ and $P$ is not predicated of $z$.

For every term $S$, for every term $P$, no $S$ is $P$ if and only if it is not the case that for some $z, S$ is predicated of $z$ and $P$ is predicated of $z$.

In a semantic analysis, then, universal affirmation and universal denial are not simple assertions. Rather, they are compound assertions with two simple predications regarding some instance falling within the scope of the subject term. That is why they require an existential quantification ('for some $z$ ') with negation ('it is not the case that...'). Even if Aristotle does not characterize 'being predicated of some' and 'not being predicated of some' in a similar fashion, we can propose the following formulations ${ }^{30}$ :

For every term $S$, for every term $P$, some $S$ is $P$ if and only if for some $z, S$ is predicated of $z$ and $P$ is predicated of $z$.

For every term $S$, for every term $P$, some $S$ is not $P$ if and only if for some $z, S$ is predicated of $z$ and $P$ is not predicated of $z$.

Now, applying the characterization of the universal denial given above, we can unpack the universal denial 'No man is white educated' in two steps. In the first step, we take apart the predications implied in the subject and predicate terms, treating the compound predicate 'being white educated' as if it were simple, thus: 'It is not the case that for some individual, he is man and he is white educated.' In the second step, we analyse the compound predicate-term into two (i.e. 'being white and being educated'), and thus reach the complete analysis: 'It is not the case that for some individual,

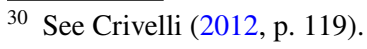


he is a man and he is white and he is educated.' A similar analysis can be given for the universal affirmation 'Every man is white educated', thus: 'It is not the case that for some individual, he is a man and he is not white educated.' Since 'is not white educated' is identical to 'is not white or is not educated' (in which 'or' is understood inclusively), we reach the analysis 'It is not the case that for some individual, he is a man and (he is not white or he is not educated)'. The foregoing considerations suggest that quantified assertions are not simple assertions in a semantic analysis. It can be concluded, then, that Aristotle can give a reasonable analysis of quantified assertions in terms of attributive predication, negative predication, affirmation (i.e. conjunction) and denial (i.e. disjunction), but he cannot reach a complete analysis without an existential quantifier ('for some individual', i.e. 'there is an individual such that...') with sentential negation ('It is not the case that...').

\section{An Issue Regarding Indirect Proof}

Having discussed the implications of Aristotle's approach for his implicit view of compound assertions, I will proceed to examine whether the distinction between simple assertion and compound assertion suffices to explain all kinds of demonstrations. Direct proof does not constitute a problem because the premises are by default assertions, either simple or compound. Indirect proof (reductio ad absurdum) requires closer examination, however. The issue is whether Aristotle can avoid suggesting that we affirm the false premise of an indirect proof, that is, the contradictory of the demonstrandum. He should avoid making that suggestion because we do not affirm that premise if we know that it is false. And that is the case when we apply the indirect proof, which Aristotle takes to be a specific kind of an argument

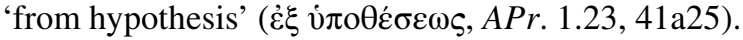

I argue that Aristotle can address the issue just raised. There are basically two alternative strategies, one inferior to the other. The first, the inferior one, is to suggest that in the case of indirect proof, Aristotle makes an exception to his principle that the premises of a demonstration are assertions. The contradictory of the demonstrandum is taken to be a premise, a 'hypothesis', and yet it is not accepted as true. This is the interpretation of Alexander of Aphrodisias, for example (In APr. 256.18-25). There is a problem with this suggestion, however. The problem is that if the hypothesis is seen to be a premise of an ordinary syllogistic argument, it remains unclear why Aristotle aligns indirect proof with the other kinds of arguments from hypothesis that need not have simple assertions as premises. We need to turn to an alternative strategy, then.
A second strategy is to understand the false premise as part of a compound assertion. ${ }^{31}$ Now the entire compound assertion is taken to be the hypothesis Aristotle has in mind. This compound assertion can be taken as a general principle. Consider, for example, the following principle: 'If something impossible follows from a given premise, then that premise is false.' When we use this principle in deriving something impossible, we have shown that the denial of the premise can be asserted as true. It is reasonable to claim that this is what giving an indirect proof is all about. Further, and importantly for the present purposes, we can assert the principle without asserting the false premise. In this line of interpretation, then, Aristotle can thwart the criticism that he could not give a reasonable account of indirect proof.

\section{Belief and a Mere Thought}

Having shown why Aristotle does not take predication to imply assertion in the case of compound assertions, I will return to consider why he is not committed to that implication in the case of simple assertions. Suppose that we do not know the answer to the question of whether the world is eternal or not (Topica 1.11, 104b16). There are different considerations for and against, and yet we lack sufficient grounds to make a decision. Given that, we can certainly understand the question without affirming or denying that the world is eternal. But why could not we simply say that the world is eternal, or that it is not eternal, without having any belief about its being eternal or not being eternal?

Of course we can, and Aristotle would not disagree. As it stands, however, he does not address this question in his logical treatises. That is because the question belongs to psychology or rhetoric rather than logic. Yet, Aristotle assumes that his logical theory is based on his psychological theory. In Int. 1, he proposes a theory of signification, according to which written marks are symbols of spoken sounds, and spoken sounds symbols of the affections of the soul (16a3-8). He thus assumes that when we say that the world is eternal, that saying must correspond to some sort of an affection of the soul. If the affection in question is not a belief ( $\left.\delta \xi^{\xi} \alpha\right)$ which comes with conviction ( $\left.\pi \dot{i} \sigma \tau \imath \varsigma\right)$, it must be a mere thought. Let us consider these two alternatives in more detail.

In $D A$. 3.3, Aristotle characterizes belief as follows: 'Belief is accompanied by conviction, for it is not possible to have a belief unless we are convinced about what we believe in' (428a19-22). This means that belief must be based on reasoning, or evidence of some kind, which produces conviction ( $\pi i \sigma \tau 1 \varsigma$ ). Typically, belief is based on

\footnotetext{
${ }^{31}$ For a recent defence of this interpretation, see e.g. Striker (2009, p. 177).
} 
other beliefs that lend support to the belief in question, and thereby make us convinced about what we believe in. Here, I assume, Aristotle follows Plato, who defines belief as the outcome of inner discussion (Sophist 264a1-b4). In some cases, however, belief can be based on mere thoughts, or how things appear to us. For example, when the sun appears to be a foot across, that is what we believe, unless some other belief contradicts that appearance, and makes us suspicious of the appearance. ${ }^{32}$ Note that the appearance in question is not necessarily accompanied by conviction. In fact, no appearance can be accompanied by conviction, except by incidence ( $\kappa \alpha \tau \grave{\alpha} \sigma v \mu \beta \varepsilon \beta \eta \kappa o ́ \varsigma)$, because appearance pertains to the perceptual part of the soul. Aristotle says: 'Conviction belongs to none of the brutes, whereas appearance belongs to many of them' (428a19-22). That is because non-rational animals lack the intellectual capacity required for being convinced of anything. In fact, non-rational animals lack the intellectual capacity required for forming predicative thoughts in the first place; instead, they live by sense perceptions, appearances and memories which are due to the perceptual capacity. By contrast, rational animals, i.e. human beings, have the capacity for forming predicative thoughts even when we are not convinced about the subject matter. We can have a mere thought about the world being eternal because we have the capacity to compare appearances, and make calculations before we acquire conviction about the object of study, and reach a conclusion. ${ }^{33}$

\footnotetext{
32 In De insomniis 2, Aristotle explains how we can be deceived by the reports of our senses as follows: 'The reason why these things happen is that the authoritative capacity and the capacity by which phantasms occur do not judge with the same power. An indication of this is that the sun appears to be a foot across, and yet often something else contradicts that appearance' (460b16-20). Aristotle thus suggests that when there is nothing to contradict the appearance of the sun as being a foot across, we go along with the appearance and are therefore deluded by it. However, if we know that the sun is larger than the inhabited world, we reject the appearance and are not deluded by it.

33 Aristotle refers to an appearance that is used in reasoning as 'cal-

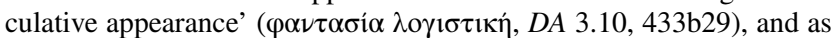

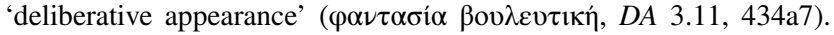
By these terms, he does not imply that there are rational (conceptual) appearances in addition to perceptual ones. What separates calculative and deliberative appearance from perceptual appearance ( $\propto \alpha \nu \tau \alpha \sigma i \alpha \alpha i \sigma \theta \eta \tau ו \kappa \eta, ~ D A ~ 3.10,433 \mathrm{~b} 29 ; 3.11,434 \mathrm{a} 5)$ is the way in which it is used in reasoning. Only animals with the capacity for reasoning can combine several appearances into one (e.g. an appearance of a horse and an appearance of a man into an appearance of a centaur), and associate an appearance with a thought, say, the concept of centaur. This explains how the appearance used in reasoning can be informed by concepts. Hence, I agree with Wedin (1988, p. 145), who observes that 'the difference between man and the other animals lies less in the distinction between two types of imagination than in the former's capacity for logos'. Cf. Modrak (2001, p. 258); Corcilius (2014, p. 85).
}

The suggestion that I am making here is this: when we say that the world is eternal, but we are not convinced about the matter, our saying corresponds to a mere thought. We entertain such a thought when we are conducting research on the matter, which implies that we measure the world by some conceptual standard such as a year as a unit of time. ${ }^{34}$ When the research is complete, we draw the conclusion which means that we assert being eternal of the world, either affirmatively or negatively.

The foregoing considerations suggest that Aristotle has resources to explain the difference between asserting and mere saying. If the considerations are correct, Aristotle relates asserting to cases in which we are convinced about something. This is the case with the results of study. Mere saying, by contrast, is related to ongoing research (though not exclusively), that is, measuring an object of study when we have not yet reached a conclusion, and formulated it as an assertion. That is why mere sayings do not play a part in demonstrations.

It is worth emphasizing that only rational animals which are capable of using language, and associating and dissociating things, can conduct research and acquire conviction. Indeed, conducting research and acquiring conviction requires that we go beyond what we can perceive by the senses, and retain by memory. It requires cooperation of the perceptual capacity and the intellectual capacity, not only in discriminating the perceptible and intelligible features of objects, but also in passing judgements on them. This is not to say that Aristotle would limit mere saying to conducting research. There are of course many other spheres of life, such as art and theatre, in which we express ourselves and imagine things without forming beliefs and making assertions. That is the reason why we are not necessarily affected when we look at pictures of frightening things in an art gallery. However, when we believe that something is

\footnotetext{
${ }^{34}$ In a practical context, the standard is something like 'good' or 'desirable'. Even if Aristotle limits his discussion on calculative and deliberative appearance to practical contexts, such as deliberating on whether a certain fig is more desirable than another one (in a context in which one wishes to choose the more desirable one), there is no reason why he could not extend his discussion to theoretical contexts such as studying whether the world is eternal. At this point, I am following Corcilius (2014, p. 85). What is common to the two cases, the practical and the theoretical, is that we consider, or 'measure' ( $\mu \varepsilon \tau \rho \varepsilon \tau \tau)$ a given object or several objects by a single standard ( $\dot{\varepsilon} \nu$ í, 434a8-9). That implies, Aristotle adds, having in mind the practical case, that we have the capacity to combine several appearances into one (434a9-10). In the practical case regarding figs, we bring the two figs in question into comparison, which requires that we combine the two appearances that we have regarding those figs into one. In the theoretical case, by contrast, the unification of appearances takes place at an earlier stage of study when we form the notion of the world based on experience ( $(\dot{\varepsilon} \mu \pi \varepsilon i \rho i ́ \alpha)$, which derives from several appearances that are stored in the memory. For the details on concept acquisition, see Metaph. A.1; APo 2.19.
} 
frightening, we are immediately affected. Aristotle makes this distinction clear in $D A 3.3$, where he notes that appearance, in the case of human beings, is up to us (427b17-24). He thus acknowledges that we can associate and dissociate things in whatever ways we like. Belief, by contrast, is not up to us in the suggested way. That is, as seen above, because belief requires conviction. It can be concluded, then, that the considerations Aristotle puts forward in the $D A$ crucially supplement and qualify those given in the De interpretatione. That is why I think it is fair to judge that the implications of Aristotle's predication theory of assertion are not as devastating as the critics believe.

Acknowledgements Open access funding provided by University of Helsinki including Helsinki University Central Hospital. This article originates from a paper read in the workshop 'Perception and Negative Beliefs - from Plato to Kant' at the University of Hamburg, 28-29 August 2014. I am very grateful to the participants of the workshop for their comments. Additionally, I would like to thank Tuomo Aho and Anssi Korhonen for several discussions on the topic, and Sonja Schierbaum and two anonymous referees for their critical observations and helpful suggestions for improvement. I could not have completed the article without the research grants awarded by the Academy of Finland, the Alfred Kordelin Foundation, the Kone Foundation, and the Swedish Collegium for Advanced Study (Riksbankens Jubileumsfond).

Open Access This article is distributed under the terms of the Creative Commons Attribution 4.0 International License (http://creativeco mmons.org/licenses/by/4.0/), which permits unrestricted use, distribution, and reproduction in any medium, provided you give appropriate credit to the original author(s) and the source, provide a link to the Creative Commons license, and indicate if changes were made.

\section{References}

Ackrill JL (1963) Aristotle's categories and de interpretatione. Clarendon Press, Oxford

Alexander of Aphrodisias, In Aristotelis Analyticorum Priorum librum I commentarius (Commentaria in Aristotelem Graeca II.1), ed. M Wallies. Georg Reimer, Berlin, 1883 (=In APr.)

Ammonius, Aristotelis de interpretatione commentarius (Commentaria in Aristotelem Graeca 4.5), ed. A Busse. Reimer, Berlin, 1897 $(=$ In. Int $)$

Ammonius, On Aristotle On Interpretation, tr. D Blank. Duckworth, London, 1996

Anonymous commentary on Aristotle's De interpretatione (Beiträge zur klassischen Philologie; Heft 95), ed. L Tarán. A. Hain, Meisenheim am Glan, 1978

Aristotle, Ethica Nicomachea, ed. I Bywater. Clarendon Press, Oxford, 1894

Aristotle, Metaphysics (2 vols), ed. WD Ross. Clarendon Press, Oxford, 1924 (=Metaph.)

Aristotle, Categoriae et liber De Interpretatione, ed. L Minio-Paluello. Clarendon Press, Oxford, 1949 (=Cat., Int.)

Aristotle, Parva Naturalia, ed. WD Ross. Clarendon Press, Oxford, 1955 (incl. De insomniis)

Aristotle, Topica et Sophistici elenchi, ed. WD Ross. Clarendon Press, Oxford, 1958

Aristotle, De anima, ed. WD Ross. Clarendon Press, Oxford, 1961 $(=D A)$
Aristotle, Analytica priora et posteriora, ed. WD Ross. Clarendon Press, Oxford, 1964 (=APr., APo.)

Aristotle, De arte poetica, ed. R Kessel. Clarendon Press, Oxford, 1964

Barnes J (1985) Theophrastus and stoic logic. In: Wiesner J (ed) Aristoteles Werk und Wirkung-Paul Moraux gewidmet I. Walter de Gruyter, Berlin, pp 557-576

Barnes J (1986) Peripatetic negations. Oxf Stud Anc Philos 4:201-214

Barnes J (1996) Grammar on Aristotle's term. In: Frede M, Striker $\mathrm{G}$ (eds) Rationality in greek thought. Clarendon Press, Oxford, pp 175-202

Barnes J (2007) Truth, etc. Oxford University Press, Oxford

Bobzien S (2002) The Development of Modus Ponens in Antiquity: From Aristotle to the 2nd Century AD. Phronesis 47:359-394

Boethius, In librum Aristotelis Peri hermeneias commentarii, ed. C Meiser. Teubner, Leipzig, 1877

Charles D, Peramatzis M (2016) Aristotle on truth-bearers. Oxf Stud Anc Philos 50:101-141

Corcilius K (2014) Phantasia und Phantasie bei Aristoteles. In: Brüllmann $\mathrm{P}$, Rombach U, Wilde C (eds) Imagination, Transformation und die Entstehung des Neuen. Beiträge zur Transformation der Antike. De Gruyter, Berlin, pp 71-87

Crivelli P (2004) Aristotle on truth. Cambridge University Press, Cambridge

Crivelli P (2012) Aristotle's logic. In: Shields C (ed) The Oxford handbook of Aristotle. Oxford University Press, Oxford, pp 113-149

Diogenes Laertius, Vitae philosophorum, ed. M Marcovich. B. G. Teubner, Stuttgart, 1999

Frede M (1974) Die stoische Logik. Vandenhoeck \& Ruprecht, Göttingen

Frege G (1918) Der Gedanke. Beträge zur Philosophie des deutschen Idealismus 1, H. 2:58-77

Frege G (1919) Die Verneinung. Eine logische Untersuchung. Beiträge zur Philosophie des deutschen Idealismus 1, H. 3/4:143-157

Geach PT (1972) Logic matters. Basil Blackwell, Oxford

Kneale W, Kneale M (1962) The development of logic. Clarendon Press, Oxford

Lukasiewicz J (1954) Aristotle's syllogistic from the standpoint of modern formal logic. Clarendon Press, Oxford

Modrak DKW (2001) Aristotle's theory of language and meaning. Cambridge University Press, Cambridge

Plato, Opera. Tomus I, ed. EA Duke, WF Hicken, WSM Nicoll, DB Robinson and JCG Strachan. Clarendon Press, Oxford, 1995 (incl. the Sophist)

Schlotter S (2006) Frege's anonymous opponent in Die Verneinung. History and Philosophy of Logic 27(1):43-58

Sextus Empiricus, Adversus mathematicos. Opera, vol. 3, ed. H Mutschmann and J Mau. B. G. Teubner, Leipzig, 1961

Stephanus, In librum Aristotelis de interpretatione commentarium (Commentaria in Aristotelem Graeca 18.3), ed. M Hayduck. Reimer, Berlin, 1885

Stobaeus, Anthologium, 5 vols., ed. O Hense and C Wachsmuth. Weidmann, Berlin, 1884-1912

Striker G (2009) Aristotle: Prior analytics, book I. Clarendon Press, Oxford

Thomas Aquinas, Expositio libri Peryermeneias (Editio altera retractata. Opera omnia iussu Leonis XIII P.M. edita. Vol. XLV.2), ed. R-A Gauthier. Vrin, Rome, 1989

Wedin MV (1988) Mind and imagination in Aristotle. Yale University Press, New Haven

Weidemann H (2014) Aristoteles: Peri hermeneias. Aristoteles Werke in Deutscher Übersetzung Band 1 Teil II. 3rd, rev. ed. Walter de Gruyter, Boston

Publisher's Note Springer Nature remains neutral with regard to jurisdictional claims in published maps and institutional affiliations. 